\title{
Olhares eruzados sobre a pandemia no Brasil
}

\section{A cross look at the pandemic in Brazil}

\author{
Geraldo Luiz de Mori* \\ FAJE
}

Recebido em: 07/07/2021. Aprovado em: 27/07/2021.

Resumo: Desde que foi declarada, no final de 2019, espalhando-se rapidamente por todo o mundo, a pandemia da COVID-19 foi objeto de várias interpretações, marcadas, inicialmente, pelas experiências da quarentena, das intervenções políticas dos estados, impondo o distanciamento social, medidas protetivas, como o uso de máscaras, novos cuidados com a higiene, sem contar as novas formas de trabalho, o home office, e as terriveis imagens dos hospitais superlotados e o número impressionante de mortos. As igrejas tiveram que ser fechadas e muitas de suas atividades foram oferecidas no formato virtual, provocando uma série de questões de caráter pastoral e teológico. No Brasil uma série de textos foi elaborada logo que se declarou a quarentena, provenientes de vários âmbitos do saber. O presente estudo propõe uma breve retomada de alguns desses textos, escritos nos primeiros meses do isolamento social, a maior parte de caráter ensaístico, perguntando-se sobre sua pertinência um ano e meio depois do início da pandemia.

Palavras-chave: COVID-19. A pandemia sob o olhar de distintos saberes. Leitura teológica da pandemia. Teologia para um mundo enfermo

Abstract: Since it was declared in late 2019, spreading rapidly throughout the world, the COVID-19 pandemic has been the object of various interpretations, marked initially by quarantine experiences, the political interventions of states, imposing social distancing, protective measures, such as the use of masks, new

* Doutor em Teologia (Centre Sèvres - Facultés Jésuites de Paris, França, 2002). Mestre em Teologia (Centre Sèvres - Facultés Jésuites de Paris, França, 1996). Bacharel em Teologia (Centro de Estudos Superiores da Companhia de Jesus - CES, Belo Horizonte, MG, 1992). Licenciado em Filosofia (Pontifícia Universidade Católica de Minas Gerais, PUC-MG, Belo Horizonte, MG, 1990). Bacharel em Filosofia (Centro de Estudos Superiores da Companhia de Jesus - CES, - Belo Horizonte, MG, 1986). Professor no Departamento de Teologia da Faculdade Jesuíta de Filosofia e Teologia - FAJE, Belo Horizonte, MG.

E-mail: geraldodemori@faculdadejesuita.edu.br 
hygiene care, not to mention the new forms of work, the home office, and the terrible images of overcrowded hospitals and the impressive number of deaths. Churches had to be closed and many of their activities were offered in a virtual format, provoking a series of pastoral and theological questions. In Brazil, a series of texts were written as soon as quarantine was declared, coming from various fields of knowledge. The present study proposes a brief review of some of these texts, written in the first months of social isolation, most of them of an essayistic nature, wondering about their relevance a year and a half after the beginning of the pandemic.

Keywords: COVID-19. The pandemic from the perspective of different knowledges. Theological reading of the pandemic. Theology for a sick world.

\section{Introdução}

Desde que foi declarada a pandemia da COVID-19, mais de 188 meses se passaram, e as cenas de horror, vistas inicialmente em Wuhan, na China, repetiram-se e espalharam-se em todos os países do mundo. Embora imaginada pela literatura de ficção e pelo cinema, e prevista por cientistas, a pandemia ganhou tal proporção que pôs radicalmente em questão as certezas da visão de mundo construídas nos últimos séculos, introduzindo de novo a vulnerabilidade e a mortalidade no horizonte de uma existência que, mesmo finita, insistia em esconder sua condição face às promessas da tecnociência e do mercado.

Muito se escreveu sobre a pandemia. Alguns desses escritos, de caráter ensaístico, oferecem interpretações de todo tipo. O presente texto retoma três das obras elaboradas no Brasil em 2020: o número 257 da Revista Cult, organizado por Daysi Bregantini ${ }^{1}$; a coletânea Reflexões sobre uma pandemia, organizada por Evânia Reich, Maria de Lourdes Borges e Raquel Cipriani Xavier²; o livro de João Décio Passos "O vírus viramundo. Em pequenas janelas da quarentena". A leitura dessas obras, de caráter panorâmico e sintético, pretende mostrar a fecundidade dos olhares cruzados na interpretação de um fenômeno tão complexo como o da pandemia. Após a apresentação dessas obras, e a título de conclusão, serão levantadas algumas questões sobre sua pertinência na interpretação de algo tão duradouro como a crise procedente da COVID-19.

1 BREGANTINI, D. Revista Cult. Ética em tempos de peste, n. 257, 2020 (Maio).

2 REICH, E.; BORGES, M. L.; XAVIER, R. C. Reflexões sobre uma pandemia. Florianópolis: Néfiponline, 2020. 


\section{A pandemia sob os olhares cruzados de diferentes saberes}

O número 257 da Revista Cult tem como título "Ética em tempos de peste" e reúne 16 textos de autores e autoras das seguintes áreas do saber: literatura, ciências sociais, filosofia, psicanálise, psicologia, teologia, direito, relações internacionais e medicina ${ }^{3}$.

$\mathrm{O}$ artigo de Raphael Luiz de Araújo 4 , "A revolta de Albert Camus contra a peste", retoma e comenta alguns aspectos da obra $A$ peste, relacionando alguns conteúdos da obra de Camus com outras do mesmo autor: $O$ estrangeiro, $O$ homem revoltado, $O$ mito de Sísifo. Como a peste retratada pelo escritor argelino, diz Araújo, "o novo coronavírus é um inimigo monótono, que exige paciência, mas também persistência e afinco". A peste "não tolera dispersão nem ignorância". Em um momento de mentiras, negligências e negacionismo urge estar atento às armadilhas do discurso político, fazendo memória do sofrimento causado pelos excessos das ações humanas e exercitando a imaginação para "enxergar o vírus invisível que nos ronda e que pode ser fatal"s.

Ivone Gebara ${ }^{6}$, no artigo "Uma perspectiva teológica feminista", evocando o livro de Jó, afirma que "nem Deus pode evitar os sofrimentos, porque a vida os exige". Por outro lado, o "contágio do vírus não conduz necessariamente à solidariedade com quem é mais pobre". Por isso, o "excesso de informações", presente nesse tempo de pandemia, "não cria solidariedade". Nesse sentido, a ética evangélica conduz para além da "mostração". A "mensagem ética, quando toca minhas/nossas entranhas, me faz enxergar no homem caído a mim mesmo, me faz dizer 'o que quero que me façam?", e me leva a concluir que "o que eu gostaria de ter como socorro é o que eu devo fazer ao/à outro/a". Na verdade, o vírus nos mostrou que, "no progresso ilimitado e seletivo que construímos estão presentes as sementes de nossa própria destruição"7.

3 As citações no corpo do texto remetem aos textos dos/as autores/as, ao ano da publicação e à página.

4 O autor é doutor em Letras pela USP e tradutor.

5 DE ARAÚJO, R. L. A revolta de Albert Camus contra a peste. In: Revista Cult, n. 257, op. cit., p. 20.

6 A autora é filósofa e teóloga, doutora em filosofia (PUC-SP) e em ciências religiosas (Louvain, Bélgica).

7 GEBARA, I. Uma perspectiva teológica feminista. In: Revista Cult, n. 257, op. cit., p. $19-21$ 
Ruy Braga ${ }^{8}$, no artigo "Os limites do carisma: ética, trabalho e necropolítica", se pergunta sobre o impacto previsível da crise da pandemia sobre o projeto necropolítico de Bolsonaro. O propósito desse projeto, observa o autor, é "mobilizar permanentemente parte da sociedade contra um inimigo interno desumanizado, e, portanto, passível de eliminação". Por outro lado, a "afinidade eletiva" entre "uma certa teologia neopentecostal e a "viração" típica do emprego informal", é uma "poderosa aliada na interpretação de como opera o neoliberalismo". De fato, a "fé em um Deus que recompensa os esforços individuais transformou-se em aliado poderoso na labuta cotidiana" e é utilizada pelo projeto necropolítico bolsonarista 9 .

Christian Dunker ${ }^{10}$, no artigo "A ética da psicanálise e a peste generalizada", recorda que mais que uma ética edipiana, a ética de Lacan é uma ética do desejo. Nesse sentido, a epidemia que nos assola não deve ser considerada como um castigo, "ela interpela a liberdade ética de cada qual para com seu desejo, ou para o serviço dos bens, em um momento de relativa suspensão jurídica". Com efeito, não somos deuses, e por essa razão a "peste nos convida a reencontrar nosso devido tamanho e a reconhecer a extensão inesperada do mundo". Assim, "enquanto a epidemia perdurar, estaremos todos na ilha da Crise, sozinhos, mas não necessariamente solitários" $"$.

Tales Ab'Sáber"12, no texto "A aceleração da história e o vírus veloz", recorda que, mais que apenas um "objeto e natural", o "vírus também é um acontecimento histórico, claramente político-ambiental", além de ser um "fato tecnológico hipercontemporâneo". Ele é portador de uma "mensagem planetária ainda enigmática e múltipla" e representa um "fato social global total". Ele é nosso "primeiro sintoma global, universalmente percebido pelos homens". Sua "face política é a denúncia radical, incontornável, das opções econômicas e sociais dos últimos $50[\ldots]$ anos da vida sobre a terra". Ao fazer "parar a máquina histórica de fato", ele realiza o "maior choque conceitual e abre o maior espaço

8 Doutor em ciências sociais pela UNICAMP e professor da USP, no Departamento de Sociologia.

9 BRAGA, R. Os limites do carisma: ética, trabalho e necropolítica. In: Revista Cult, n. 257, op. cit., p. 23-24.

10 Psicanalista, doutor em psicologia pela USP e professor na mesma instituição.

11 DUNKER, C. I. L. A ética da psicanálise e a peste generalizada. In: Revista Cult, n. 257, op. cit., p. 31.

12 Psicanalista e doutor em psicologia clínica pela USP, professor na UNIFESP. 
potencial de transformação que o mundo capitalista é capaz de intuir". Por isso, sua mensagem e impacto "configuram agora mesmo o tempo de uma terceira globalização contemporânea", sendo por isso "revolucionário" e tornando-se o "único valor reconhecido universal de unidade entre os homens no mundo do mercado". Ele universaliza "a transmissão da morte, utilizando-se dos próprios mecanismos normais da vida hiperveloz do mundo e mercado contemporâneo". Dessa forma, ele torna todos os seres humanos "iguais diante de sua experiência, suspendendo radicalmente por um tempo os contratos e valores". O antídoto que reverte nosso modo viral e mortífero é a "ação universal de desacelerar a vida"'3.

O texto de Carla Rodrigues e Suely Aires ${ }^{14}$, "Coreia do Sul, Brasil... ou o pior", evoca o filme ganhador do Oscar de 2020, Parasita, vendo nele uma metáfora do tempo presente. À luz de Judith Butler, as autoras afirmam que é "pela vulnerabilidade, perda e luto", que se pode pensar a pandemia. "Somos desfeitos uns pelos outros [...], pelo toque, pelo cheiro, pelo tato, pela perspectiva do toque". Na pandemia, porém, "a única forma de evitar a COVID-19 é evitar o outro, o toque, o tato, o contato", aquilo que constitui esse "tênue nós". Essa interdependência constitutiva do "nós" supõe a "responsabilidade ética com toda forma de vida". Nesse sentido, "qualquer proposta de cuidado precisa ser coletiva e ampliada, de modo que todas as vidas contem como vidas". A pandemia nos obriga a "experimentar de maneira sensível a verdadeira amplitude das catástrofes globais". No Brasil, porém, a ênfase em "salvar a economia"”, parece ignorar isso, repetindo um velho slogan do neoliberalismo ${ }^{15}$.

Ernani Chaves ${ }^{16}$, no artigo "Sobreviver, mais uma vez!", aponta a necessidade de "desmontar as metáforas", sobretudo as que são privilegiadas no enfrentamento da pandemia, que são metáforas guerreiras. Segundo ele, o conceito de "biopolítica", privilegiado na filosofia política nas últimas décadas, pretende explicar como o "poder é exercido em nossa época" e como "a dinâmica do capitalismo se metamorfoseia para manter sua hegemonia". Recorrendo a Esposito, o autor afirma que, mais que o combate do "mal", no caso da pandemia trata-se de "combater sua

13 AB'SÁBER, T. A aceleração da história e o vírus veloz. In: Revista Cult, n. 257, op. cit., p. 34-35, 38-42.

14 Carla Rodrigues, doutora em filosofia pela PUC-Rio e professora de filosofia na UFRJ; Suely Aires, doutora em filosofia da psicanálise pela UNICAMP e professora da UFBA.

15 RODRIGUES, C.; AYRES, S. Coreia do Sul, Brasil... ou o pior. In: Revista Cult, n. 257, op. cit., p. 47-49.

16 Doutor em filosofia pela USP e professor de filosofia na UFPA. 
circulação descontrolada", protegendo "o corpo social exposto a processos de contaminação descontrolada". No fundo, combate-se o "inimigo invisível por meio de um regime de visibilidade total de nossas armas". O outro que não revela suas armas se torna então inimigo. Por um lado, a dinâmica da globalização infiltrou em nós o medo dos migrantes, dos refugiados, "desses "outros" sempre perigosos". Por outro lado, ela exacerbou a "medicalização da política e a politização da medicina". Todo esse processo levou a um deslize em um "regime emergencial", que nos coloca em um estado permanente de exceção. No Brasil, vige o princípio biopolítico de "deixar morrer para poder viver", legitimando-se a morte dos que são vistos como "perigo biológico para os outros"17.

Para Marcio Sotelo Felippe ${ }^{18}$, no artigo "Pandemia: a antítese entre sociedade e mercado", a pandemia é "uma radiografia do capitalismo". Ela expõe a diferença de consequências e sofrimentos que o cotidiano oculta e mostra "cruamente o injusto, o irracional, a inadequação de um modo de produção que exclui a maior parte da população dos bens materiais necessários para a sobrevivência digna e do acesso a bens culturais e estéticos". Para o neoliberalismo, fonte desse sistema, "não há sociedade, há indivíduos que lutam por seus interesses e olham antes para si próprios. A vida social resume-se ao mercado. Quem está fora do mercado está fora da sociedade" 19 .

Tarso de $\mathrm{Melo}^{20}$, no artigo "O despotismo delivery do capital", discute a mediação dos aplicativos de mão de obra, sobretudo em tempos de pandemia. Alguns os veem como "aplicativos de serviços", que "possibilitam a comunicação entre consumidores e empreendedores", e outros já se deram conta que se trata de "aplicativos de exploração de mão de obra". Eles não só facilitam a vida dos consumidores, mas são um mecanismo de exploração e de acumulação de capital para seus proprietários. Eles instituíram um novo "estilo de vida", obrigando a classe trabalhadora a se "travestir de empreendedora para se encaixar nos padrões terríveis que as empresas impõem". A questão que surge para o pós-pandemia é: como "dizer que voltaremos à "normalidade" quando o normal é a precarização extrema das vidas?" De fato, "nosso estilo de

17 CHAVES, E. Sobreviver, mais uma vez! In: Revista Cult, n. 257, op. cit., p. 52-56.

18 Advogado e mestre e teoria geral do direito pela USP.

19 FELIPPE, M. S. Pandemia: a antítese entre sociedade e mercado. In: Revista Cult. n. 257 , op. cit., p. $58,61$.

20 Escritor, advogado, doutor em filosofia do direito pela USP. 
vida, cheio de facilidades, comodidades e até mesmo segurança ante a ameaça do vírus, só é possível porque grande parcela da população está sendo submetida em níveis radicais"21.

Aislan Marco Macieira ${ }^{22}$ inicia o artigo "Arbeit Macht Frei": Brasil, 2020" comentando os dizeres da placa de entrada no campo de concentração de Auschwitz, que havia sido roubada em 2009, cuja tradução é "o trabalho liberta". Essa placa foi objeto de obras de Primo Levi e volta ao centro dos debates em tempos de pandemia, sobretudo nos discursos dos que querem assegurar seus ganhos em detrimento da saúde dos trabalhadores. Segundo o autor, quando a elite econômica brasileira "escolheu colocar um típico reverberador das ideias fascistas no poder, escolheu se distanciar ainda mais dos indesejáveis". De fato, todo autoritarismo busca "desfrutar do trabalho alheio", negando-lhe ao mesmo tempo "qualquer valor humano". O nazismo buscou transformar os prisioneiros em "bons animais de trabalho", "incapazes de se rebelar e criticar". É nisso que a "elite do atraso" do Brasil busca transformar sua classe trabalhadora. Primo Levi, conclui o autor, afirma que "cada época tem seu fascismo", ao qual se chega de muitos modos, nem sempre com o terror da intimidação policial, mas sempre "negando ou distorcendo informações, corrompendo a justiça, paralisando a educação, divulgando de muitas maneiras sutis a saudade de um mundo no qual a ordem reinava", travestindo-se em defensor da família, do povo, da tradição e da pátria ${ }^{23}$.

Alvaro Bianchi ${ }^{24}$, no texto "Maquiavel demoníaco", reflete sobre o papel do filósofo florentino que, segundo ele, à luz do comentário de Benedetto Croce, "descobriu a autonomia da política levada a cabo por Maquiavel". Trata-se de uma "descoberta filosófica", mas também moral, pois em sua obra ele rebelou-se contra uma certa moral cristã, sobretudo a da autoridade e do poder da igreja. Por isso, o antimaquiavelismo é "conservador ou reacionário", visto como "demoníaco"25.

O texto de Pedro Augusto Gravatá Nicoli e Regina Stela Corrêa Vieira ${ }^{26}$ "Cuidado em surto. Da crise à ética", inicia afirmando que na

\footnotetext{
21 DE MELO, T. O despotismo delivery do capital. In: Revista Cult, n. 257, op. cit., p. 63-64.

22 Doutor em Letras pela USP.

MACIEIRA, A. C. “Arbeit Macht Frei”: Brasil 2020. In: Revista Cult, n. 257, op. cit., p. 68-69. 
"crise global, o cuidado se torna a chave indispensável para compreender as muitas dimensões dos problemas gerados, agravados ou expostos pelo vírus". Nesse sentido, cuidar, de si, do outro, do próximo, dos seus, de quem é mais vulnerável, dos idosos, de quem cuida, da sociedade, é essencial para sair do "labirinto assustador de incertezas que toma proporções civilizacionais". O cuidado é também "atenção, presença, antecipação, trato das angústias". Apesar desta centralidade do cuidado, as profissões que o assumem são mal reconhecidas e remuneradas. A crise do coronavírus mostrou, porém, nossa radical dependência uns dos outros e a necessidade do cuidado para existir ${ }^{27}$.

Renan Quinalha ${ }^{28}$, no texto "Desafios à democracia", recorda que a metáfora da "guerra" e termos como "quarentena", "isolamento vertical", "distanciamento social", "orçamento de guerra", "atividades essenciais" tornaram-se comuns na pandemia. $\mathrm{O}$ autor se pergunta como essas medidas se relacionam com o direito, dependendo de suas normas e instituições e impactando-as? Muitas medidas restritivas foram instituídas, limitando o direito de ir e vir, os direitos trabalhistas. Ao mesmo tempo, os governos tiveram que criar ferramentas para responder com agilidade à situação da emergência sanitária e a concentração desses poderes em suas mãos é uma ameaça à democracia. Para conter essa ameaça é importante que o executivo seja supervisionado pelo legislativo e pelo judiciário, que as medidas de exceção sejam limitadas ao necessário e que os poderes sejam delegados somente durante o estado de emergência. No caso do Brasil, porém, a tragédia sanitária coincide com a "convergência entre autoritarismo político, ultraliberalismo econômico e conservadorismo moral" 29 .

O texto de Táki Athanássios Cordás ${ }^{30}$ "A economia deve esperar" apresenta dados do IDH do Brasil nos últimos anos, recordando os grandes desequilíbrios que imperam no país no setor socioeconômico, que na pandemia atingem sobretudo o âmbito da saúde. A quarentena, segundo o autor, "tem impacto fundamental sobre três elementos importantes do ser humano: a autonomia, a competência e a sociabilidade" ${ }^{31}$.

27 NICOLI, P. A. G.; VIEIRA, R. S. C. Cuidado em surto: da crise à ética. In: Revista Cult, n. 257, op. cit., p. 75-77.

28 Advogado, doutor em relações internacionais pela USP e professor na UNIFESP.

29 QUINALHA, R. Desafios à democracia. In: Revista Cult, n. 257, op. cit., p. 79, 81.

30 Doutor em medicina pela USP e professor na mesma instituição.

31 CORDÁS, T. A economia deve esperar. In: Revista Cult, n. 257, op. cit., p. 89. 
O texto de Silvana de Sousa Ramos ${ }^{32}$, "Fragmentos de um diário", recolhe as reflexões da autora em algumas datas do início da quarentena, com associações livres entre a data do calendário e questões levantadas pela pandemia. Frei Betto ${ }^{33}$, no texto "A pandemia e suas implicações éticas", conclui a coletânea, afirmando que "é em momentos de crise como esse que as pessoas se revelam". Segundo o autor, a questão ética fundamental desse tempo é a do valor da vida humana. Outra dimensão ética levantada por esse tempo é a do "conflito entre solidariedade e produtividade" 34 .

O interesse desse conjunto de textos para a teologia é seu caráter multidisciplinar. Predominam como chaves de leitura questões ligadas à economia e à política, centrais também nos outros textos que serão apresentados, e questões de caráter jurídico, literário, que ajudam a penetrar na profundidade da crise desencadeada pela COVID-19 no Brasil. Esses distintos olhares são importantes para a reflexão teológica, que tem que discernir, dentre as muitas leituras da realidade, os elementos que demandam a inteligência da fé.

\section{A pandemia sob os olhares cruzados da filosofia}

A obra Reflexões sobre uma pandemia, reúne 15 artigos, todos da área da filosofia. Algumas questões levantadas pelos autores coincidem com a da coletânea anterior, mas são assim mesmo apresentadas, pois mostram a convergência do cruzamento de olhares.

O artigo de Alessando Pinzani ${ }^{35}$, "Fraqueza do Estado e elitização da cidadania na América do Sul: lições políticas da pandemia", afirma que a "crise da Covid-10 recolocou no centro da cena política um ator que desde a crise econômica de 2008/2009 tinha sido esquecido como protagonista, a saber, a figura do Estado" 36 . No texto "A pandemia e o individualismo que nunca existiu”, Bárbara Buril ${ }^{37}$ pergunta-se se é

\footnotetext{
32 Doutora em filosofia pela USP e professora na mesma instituição.

33 Frade dominicano e escritor. políticas da pandemia. In: REICH, E.; BORGES, M. L.; XAVIER, R. C. Reflexões sobre uma pandemia, op. cit., p. 22.

BETTO, F. A pandemia e suas implicações éticas. In: Revista Cult, n. 257, op. cit., p. 99.

Professor de filosofia na UFSC.

PINZANI, A. Fraqueza do Estado e elitização da cidadania na América do Sul. Lições Doutoranda na UFSC.
} 
"possível aprender alguma lição a partir do sofrimento". Segundo ela, a história mostra que o sofrimento ensina muito pouco, embora possua um "poder revelatório", pois "nos revela agora, em luz neon, aspectos de nossa forma de vida que não víamos muito bem quando a vida funcionava em "modo normal"" 38 . Cinara Nahra ${ }^{39}$, no artigo "Tem futuro a humanidade?", evoca o "doomsday clock", relógio fictício criado pelo Bulletin of the Atomic Scientists, que, desde 1947, marca o quão próximo do fim se encontram o mundo e a humanidade. A catástrofe prevista por muitos cientistas, "chegou mais cedo do que pensávamos, na forma de um vírus altamente contagioso". Ela não ameaça destruir permanentemente a humanidade, mas é um alerta e traz várias lições, como a do despertar para uma rede de solidariedade e altruísmo, que aponta para a capacidade humana de "suplantar o egoísmo"

Cristina Consani ${ }^{41}$, no artigo "A soberania dos Estados e os limites das instituições internacionais na pandemia do coronavírus", mostra o papel das instituições internacionais no mundo globalizado. Em diálogo com Habermas, a autora discorre sobre a "forma que poderia assumir uma estrutura político-jurídica internacional capaz de tomar decisões vinculantes e obrigatórias em casos nos quais estão em jogo a vida, a integridade física e os direitos dos indivíduos submetidos ao poder dos Estados" $"$. A autora reconhece, porém, que uma pandemia como a do coronavírus mostra que seu potencial de letalidade pode ser superior ao de muitas guerras e que as organizações internacionais têm exercido um papel frágil na defesa e na proteção dos direitos humanos.

Darlei Dall'Agnol ${ }^{43}$, no artigo "Reflexões bioéticas sobre a COVID-19", indaga-se sobre o papel da ética no combate ao coronavírus, propondo três tarefas para a filosofia: reforçar o papel da ciência no enfrentamento da pandemia; refletir sobre as novas formas de relacionamento; discutir sobre os inúmeros dilemas éticos que se apre-

38 BURIL, B. A pandemia e o individualismo que nunca existiu. In: REICH, E.; BORGES, M. L.; XAVIER, R. C. Reflexões sobre uma pandemia, op. cit., p. 31.

39 Professora de filosofia na UFRN.

40 NAHRA, C. Tem futuro a humanidade? In: REICH, E.; BORGES, M. L.; XAVIER, R. C. Reflexões sobre uma pandemia, op. cit., p. 36-37.

41 Professora de filosofia na UFPR.

42 CONSANI, C. F. A soberania dos Estados e os limites das instituições internacionais na pandemia do coronavírus. In: REICH, E.; BORGES, M. L.; XAVIER, R. C. Reflexões sobre uma pandemia, op. cit., p. 46.

43 Professor de filosofia na UFSC. 
sentam $^{44}$. O autor participa de um grupo de filósofos que busca oferecer respostas a alguns dilemas bioéticos levantados pela pandemia, como o uso de recursos escassos no sistema de saúde e o uso de medicamentos ainda não comprovados.

Delamar José Volpato Dutra ${ }^{45}$, no artigo "A COVID-19 e o iluminismo", recorda que "a ciência aponta para o iluminismo, não obstante, a COVID-19 parece ter posto o iluminismo de quarentena, nos seus mais diversos sentidos: (1) científico, (2) jurídico-político, (3) moral, (4) econômico"46. Com efeito, a doença desafia o iluminismo científico, pois, ao invés de vacinas e remédios, tem que recorrer à segregação das pessoas. Ela desafia ainda o aspecto jurídico-político, pois os Estados se viram incapazes de garantir o bem-estar das pessoas e a liberdade individual. Ela desafia, também, o iluminismo da moral deontológica, pois as escolhas tomadas agora são apenas um indício do que estaria por vir, como a escolha de qual vida salvar, a que tem menos chances ou a que tem mais chances de se recuperar? O iluminismo moral deontologista se manifesta, por sua vez, na economia, que defende salvar empregos e não vidas. $\mathrm{O}$ vírus mostra, enfim, as falhas do iluminismo econômico-social, pois penaliza os mais vulneráveis.

Érico Andrade ${ }^{47}$, no artigo "Vários mundos para uma só pandemia: contra a universalidade do discurso filosófico", evoca as diferenças sociais relacionadas com a crise da pandemia. Segundo ele, contrariamente ao que muitos afirmam, a pandemia não possui nada de democrático, mas acentua muito mais do que elimina a desigualdade social. Em países como o Brasil, observa o autor, o vírus, tanto sua contaminação quanto suas consequências, não afetam da mesma maneira as pessoas. Por isso, "não existe o mundo pós-pandemia. Existem mundos", que são afetados "em tempos e espaços distintos" 48 . O tempo e o espaço são relativos à classe, à raça e ao gênero. A circulação do vírus se dá de forma indiscriminada, mas a possibilidade de lidar com essa circulação e se proteger depende do contexto no qual alguém se encontra.

44 DALL'AGNOLL, D. Reflexões bioéticas sobre a COVID-19. In: REICH, E.; BORGES, M. L.; XAVIER, R. C. Reflexões sobre uma pandemia, op. cit., p. 53.

45 Professor de filosofia na UFSC.

46 DUTRA, D. J. V. A COVID-19 e o iluminismo. In: REICH, E.; BORGES, M. L.; XAVIER, R. C. Reflexões sobre uma pandemia, op. cit., p. 62.

47 Professor de filosofia na UFPE.

48 ANDRADE, E. Vários mundos para uma só pandemia: contra a universalidade do discurso filosófico. In: REICH, E.; BORGES, M. L.; XAVIER, R. C. Reflexões sobre uma pandemia, op. cit., p. 72. 
Evânia Reich", no artigo "Entre a cruz e a espada", reflete sobre o limite das liberdades individuais na mão de Estados autoritários, no combate à epidemia, em diálogo com o filósofo coreano Chul Han, que afirma que os países autoritários da Ásia controlaram melhor a pandemia que os países da Europa, e o filósofo esloveno Slavoj Zizek, para o qual o vírus pode derrubar o capitalismo com um golpe mortal. Discordando de Zizek, a autora diz que "o vírus não somente não é capaz de revolução, como ele nos isola, nos individualiza, nos torna mais egoístas" ${ }^{50}$. Felipe Campello ${ }^{51}$, no texto "De onde fala a filosofia?", em diálogo com Agamben, pergunta-se pelo lugar de fala da filosofia. Agamben, observa o autor, "definiu em um de seus artigos a epidemia como "uma invenção". Esse tipo de postura, observa Campello, é tributário da herança metafísica da filosofia e de sua pretensão ao saber universal. Mas, "qual é esse universal, de quem e para quem?" O autor pensa que a pretensão universalista é marcada por questões de injustiça epistêmica e política, que definem "quem está dentro o quem está fora, quem pode falar e quem é silenciado, quais falas, enfim, importam para o debate filosófico?" Segundo ele, a "arrogância empobrece a filosofia”. Somente quando ela sai de seu "autocentramento, sem se furtar do diálogo", ela pode ser significativa. Mas, para que isso aconteça, ela precisa também exercer sua imaginação, ousando pensar ideias e alternativas que ainda não estão dadas e pensadas ${ }^{52}$.

No texto "Suspensão", Janyne Sattler ${ }^{53}$ descreve a incerteza do futuro e o terror do presente, perguntando-se sobre o que esperar num mundo tomado pela pandemia. Ela fala de "pânico da verdade", que se revela nas políticas higienistas que "escancaram a cor da classe social, daqueles que morrem primeiro", para os quais sempre houve "a vala comum, inominada e sem lembrança, cujo luto nós nunca fizemos no país da interminável, irreparável, escravidão" ${ }^{54}$. Joel Klein ${ }^{55}$, no artigo

49 Pós-doutoranda na UFSC.

50 REICH, E. Entre a cruz e a espada. In: REICH, E.; BORGES, M. L.; XAVIER, R. C. Reflexões sobre uma pandemia, op. cit., p. 81.

51 Professor de filosofia na UFPE.

52 CAMPELLO, F. De onde fala a filosofia? In: REICH, E.; BORGES, M. L.; XAVIER, R. C. Reflexões sobre uma pandemia, op. cit., p. 83, 85-87.

53 Professora de filosofia na UFSC.

54 SATTLER, J. Suspensão. In: REICH, E.; BORGES, M. L.; XAVIER, R. C. Reflexões sobre uma pandemia, op. cit., p. 92.

55 Professor de filosofia na UFPR. 
"O papel político da comunidade científica e dos intelectuais e o caso da pandemia do coronavírus", afirma que nas esferas da religião, da política e da economia certos grupos "vêm fazendo uso de uma estratégia ideológica que naturaliza as suas escolhas e os desresponsabiliza". Esses grupos são anti-intelectualistas e anti-iluministas. Como "um vírus resistente, grande parte da população, dos governantes e economistas desenvolveram resistência frente ao tratamento da perspectiva crítica e científica". O autor analisa as propostas da tradição político-filosófica diante do saber crítico: a da "criação de um governo de ilustrados" e tecnocrático, a da escuta de intelectuais que se expressam na esfera pública e democrática. Para o autor, é importante explorar uma terceira opção, a da "possibilidade do desenvolvimento de uma teoria da separação dos poderes que não envolvesse apenas 3, mas 4 poderes: executivo, legislativo, judiciário e um 'conselho' que congregasse intelectuais reconhecidos de diversas áreas, cuja atuação e poder de decisão fosse inserido no design institucional do estado" $"$.

Leon Farhi ${ }^{57}$, no artigo "Covid-10 e ubupoder-19", associa a crise da pandemia com a do capitalismo, perguntando-se "em que grau a morte entrava o dinamismo do capital?" Por um lado, diz o autor, o número impressionante de mortos pela pandemia será assimilado por esse dinamismo. Por outro, em muitos países houve suspensão parcial do sistema econômico. As medidas tomadas abalam a existência do capitalismo atual, indicando que o problema não é o vírus em si, mas as medidas que o combatem. No Brasil, porém, continua o autor, não se pode dissociar a COVID-19 do ubupoder ${ }^{58}$, cuja ousadia covarde, atrevimento e desmedida "não para diante de nenhum escrúpulo". O ubupoder "não é apenas arbitrário, grotesco, violento, ele é desejado por uma relevante parcela social", ele "move e é movido por um amplo movimento social de massa", de caráter fascista. De fato, "é como massa (mas fechada, de guerra, com líder, fascinada) que o fascismo se move socialmente". $\mathrm{O}$ atual fascismo brasileiro não é "o eterno retorno do Mesmo (virtual), tem sua aparência histórica própria: como neofascinação". Com efeito,

56 KLEIN, J. O papel político da comunidade científica e dos intelectuais e o caso da pandemia do coronavírus. In: REICH, E.; BORGES, M. L.; XAVIER, R. C. Reflexões sobre uma pandemia, op. cit., p. 98. 100. 
"o neo do ubupoder-19 são seus aspectos teocráticos. [...] Superstição, medo, medo, ódio, ódio, destruição. Nostalgia metafísica do nada". A história mostra que o fascismo surge quando o capital fragilizado "se alia à pulsão de morte. Tudo o que é Outro se torna alvo do ódio (floresta, cerrado, oceano, indígena, quilombola, criminoso, pobre fraco, velho, virótico...)", e deve, portanto, "ser exterminado". Por isso, "Nossa época diz - aborto, eutanásia, não; tanatopolítica, sim" $"$.

Maria de Lourdes Borges ${ }^{60}$, no texto "O mal na natureza e o mal humano", retoma a questão do mal, associada à pandemia, em diálogo com Kant, a partir de três enfoques: o da ilusão iluminista, que acreditava "no domínio total da natureza", levando à falsa esperança de que nada vindo da natureza afetaria o ser humano, ou, caso isso acontecesse, haveria remédio para conter; o do esquecimento do Estado, realizado através de políticas econômicas liberais, deixando vários países sem condições de atendimento à população atingida pela COVID-19; o da banalidade do mal, expressa em sadismo, escárnio e negacionismo ${ }^{61}$. Milene Tonetto ${ }^{62}$, no artigo "Ética global, direitos humanos e a pandemia da COVID-19", mostra as perspectivas a partir das quais abordar a ética global: a da globalidade, que deveria levar a acordos internacionais, para que todos tenham acesso a medicamentos, vacinas e tratamento; a da muldisciplinaridade, que mostra a importância da ciência para justificar e fundamentar os argumentos morais e jurídicos; a que combina teoria e prática, que aponta para a participação de especialistas em ética, para que se obtenha soluções práticas justas para o controle da pandemia ${ }^{63}$. O último texto, de Vilmar Debona ${ }^{64}$ e Cláudia Dias ${ }^{65}$, "Alegria maligna", indaga, à luz de Shopenhauer, a razão do riso macabro relacionado à pandemia, presente em algumas manifestações no Brasil. Os princípios shopenhaurianos que motivam o indivíduo para suas ações são: o egoísmo, que busca causar dor a outrem como meio para atingir os fins do agente; a maldade, que

59 NETO, L. F. Covid-10 e ubupoder-19. In: REICH, E.; BORGES, M. L.; XAVIER, R. C. Reflexões sobre uma pandemia, op. cit., p. 106, 111-114.

60 Professora de filosofia na UFSC

61 BORGES, M. L. Sobre o mal da natureza e o mal humano. In: REICH, E.; BORGES, M. L.; XAVIER, R. C. Reflexões sobre uma pandemia, op. cit., p. 122.

62 Professora de filosofia na UFSC.

63 TONETTO, M. C. Ética global, direitos humanos e a pandemia da COVID-19. In: REICH, E.; BORGES, M. L.; XAVIER, R. C. Reflexões sobre uma pandemia, op. cit., p. 125.

64 Professor de filosofia na UFSC.

65 Doutoranda em filosofia política na UFPR. 
leva a sentir prazer com a dor alheia; e a compaixão, que quer o bem do outro. Nesse sentido, a "alegria maligna" é uma das expressões mais assustadoras do mal moral", "o sinal mais inequívoco de coração mau e de nulidade moral", que revela um "diabolismo, uma potência de alguma forma inumana". O Brasil, concluem os autores, "atravessa esse momento de dor, sofrimento e morte generalizados como uma terra repleta de individualidades capazes daquele 'riso do inferno', referido por Shopenhauer em sua obra"66.

A abordagem filosófica, proposta na coletânea analisada, privilegia o viés ético e político, aprofundando algumas das questões levantadas pelos textos analisados na primeira parte desse estudo. Seu interesse, numa reflexão teológica, é o de estabelecer relações entre essas dimensões fundamentais da existência humana, que são a ética e a política, para os quais, como se verá na obra seguinte, a teologia a teologia deve se voltar.

\section{Um olhar teológico da pandemia}

Uma das primeiras obras teológicas escritas no Brasil sobre a pandemia foi o livro de João Décio Passos. Suas reflexões, organizadas em três partes, 1 . A pandemia do coronavírus; 2 . Significados da pandemia; 3. O dia seguinte da pandemia, "nasceram durante os dias da quarentena, como pequenas janelas que quiseram abrir algumas perspectivas presentes ou escondidas na grande crise". Segundo o autor, não é uma obra sistemática, mas olhares "sobre os fatos que se desdobravam, à medida que a crise mundial mostrava seus muitos aspectos" envolvendo todos em seu drama ${ }^{67}$.

A primeira parte da obra possui sete textos. O primeiro "E de repente o mundo parou...", evoca a música de Raul Seixas "O dia em que a terra parou", sonho-profecia de um mundo no qual tudo pararia. Num breve sobrevoo sobre as últimas décadas, o autor observa que parecia que nelas "as forças de ruptura sistêmica de fato se exauriam", vencendo a "ideia de um mundo estável e imutável". Nesse mundo do eterno presente, o "ato de consumir, encaixado ao mercado, costurou a síntese mais perfeita entre os desejos insaciáveis da alma humana e as

66 DEBONA, V.; DIAS, C. A. Alegria maligna. In: REICH, E.; BORGES, M. L.; XAVIER, R. C. Reflexões sobre uma pandemia, op. cit., p. 137-138, 142.

67 PASSOS, J. D. O vírus vira mundo: em pequenas janelas da quarentena. São Paulo: Paulo, 2020. p. 9. 
dinâmicas de produção do mercado". O "ciclo de produção-consumo incessante dispensa qualquer promessa de futuro". O bem-estar atual e acessível torna-se "totalizante, onipotente e onipresente". Porém, continua o autor, nessa "cultura estável da felicidade presente" eclodiu a pandemia, "com seus apelos urgentes e com seu vírus corrosivo", atravessando fronteiras e levando à busca de uma "política desesperada da salvação imediata das populações e da economia". As crises que ela provocou "desbancam as leituras seguras do mundo, as religiosas e as políticas; mostram a fragilidade da vida e dos poderes e trazem à tona o mais essencial: a preservação da vida". Como tão bem anteviu Raul Seixas, sintetiza o autor concluindo seu texto, "não esperávamos, não foi um sonho, mas vimos a terra parar!" ${ }^{\prime 68}$.

No texto "A força de um vírus", o autor aponta o diferencial da atual epidemia: sua velocidade, parecida à da atual mobilidade humana planetária, tradução da "vida planetariamente conectada". Por isso, apesar de o vírus e outros micro-organismos serem constitutivos da vida no planeta, o novo coronavírus está "escrevendo a história das epidemias e de seus efeitos". De fato, a pandemia revela a "força implacável" da natureza, "fazendo os seres humanos tomarem consciência de sua fragilidade", uma vez que "viver e morrer, sobreviver e matar compõem o paradoxo natural do sistema vivo no planeta terra", e o ser humano, através da assimilação do vírus ou através da vacina, busca restabelecer o caos criado pelo vírus e impor a ordem ${ }^{69}$.

O terceiro texto, "As viagens do vírus", analisa a dinâmica própria do vírus, "ser hospedeiro e mutante". Segundo o autor, "as viroses são nossas companheiras de viagem desde que a vida é vida". Embora seja natural, a contaminação viral está condicionada pela variável cultural, sobretudo as interações sociais decorrentes dos deslocamentos. Quanto "mais intensa e extensa for nossa socialização, mais intensa e extensa serão as transmissões virais". O caso da COVID-19 mostra que "o mapa econômico é também o mapa do vírus". Foram "os mais ricos que introduziram o vírus em seus países". Nesse sentido, pode-se dizer que o "coronavírus viaja e tem classe social", embora sejam os mais pobres os que "pagaram o maior preço" do contágio ${ }^{70}$.

\footnotetext{
68 PASSOS, p. 16-18.

69 PASSOS, p. 19-21, 24.

70 PASSOS, p. 26-28.
} 
No texto "Derrubando os muros", Décio Passos diz que ainda não se sabe como ficará o planeta depois que a crise pandêmica passar. É importante, porém, lembrar que o mundo já vivia uma crise de ordem política e econômica, cuja solução tinha sido antevista por certos grupos religiosos e políticos como "retorno aos fundamentos esquecidos da civilização ocidental: a família, a identidade cristã, a moralidade". Os projetos políticos de ultradireita se inspiram nesses fundamentos, criando inimigos (comunismo, ideologia de gênero, refugiados/migrantes, islamismo), propondo muros de proteção de caráter "aporofóbicos" e invocando o nome de Deus como garante dessa pretensa identidade perdida. O coronavírus "atravessou as fronteiras e colocou em cheque as supostas seguranças e os fechamentos das nações", adentrando "nos corpos físicos das pessoas de todas as classes, nos corpos fechados das nações muradas, no corpo das ideologias segregacionistas e no corpo autônomo da economia de mercado". O autor se pergunta se depois da pandemia surgirá uma "civilização sem muros"

No texto "A casa e a rua" Passos mostra como a dialética casa e rua foi totalmente modificada com a pandemia, fazendo com que, de repente, a casa virasse o "mundo habitado por todos", mundo no qual todos tiveram que "reaprender a conviver". Refúgio do perigo, a casa faz lembrar o "papel das casas nos rincões do Brasil rural", onde eram "refúgio para perigos reais e imaginários", embora, no atual contexto, tenham se tornado lugar de home office e de conexão com amigos, e parentes. $\mathrm{O}$ inimigo, nesse contexto, mora fora, é invisível e pode atacar a qualquer momento. Como no "passado, todos gritam por socorro sobrenatural". A pedagogia do vírus é cruel, recorda o autor citando Boaventura de Sousa Santos. De fato, a casa não é mais a mesma do ambiente rural, como tampouco o é a vida familiar. Em geral "vivemos um isolamento mundializado, uma casa conectada em redes". Porém, um primeiro passo foi dado, levando a família a um encontro consigo mesma, conectando-a "com a sociedade", colocando-a em relação de diálogo e reciprocidade com os sujeitos que a compõem, atentando aos problemas da comunidade local, da nação e do planeta. Uma nova relação entre a casa e a rua está em construção, articulando, numa nova simbiose, o próximo e o distante ${ }^{72}$.

No texto "Impactos e medos", Passos analisa duas reações provocadas pela pandemia: medo e fuga. Hans Jonas, diz ele, falava

71 PASSOS, p. 31-32, 34. 
da "heurística do medo" como "postura necessária para a construção ética da convivência humana planetária". O temor da morte, forte nessa pandemia, contrapôs-se ao medo da crise econômica, instaurando-se um dilema "entre dois medos: o da morte ou o da falência". No texto seguinte "A crise dentro da crise, dentro da crise", o autor diz que na compreensão da pandemia predominou a categoria crise, que abrange desde a experiência individual à planetária, esta última tendo aspectos econômicos, o do fim do estado de bem-estar social, e políticos, o da crise da democracia liberal e da sedução pelo autoritarismo. No Brasil essas crises se expressaram nas seguintes rupturas: a) entre poderes: executivo e legislativo, STF e executivo; b) entre leituras sobre a pandemia: a das ciências e associações de saúde e a do negacionismo do executivo; c) entre a salvação da economia e a salvação de vidas; d) entre a concepção neoliberal e a concepção social do Estado; e) entre o projeto de poder defendido pelo presidente e os projetos de outros candidatos ${ }^{73}$.

A segunda parte do livro, "Os significados da pandemia", também composta de 7 textos, retoma e aprofunda alguns aspectos já presentes na primeira parte e acrescenta outros. No primeiro texto "As interpretações do coronavírus", o autor afirma que no futuro se verá que a pandemia foi um momento em que a 'humanidade olhou para si mesma, ficou pasmada com o inédito e [...] pensou sobre os rumos da vida planetarizada". As ofertas de leituras, de verdades e de soluções para esse período serão diversas, marcadas por dissensos, desde as que se pautam nas ciências, passando pelas que negam a existência da pandemia e as que recorrem às crenças religiosas para explica-la. Com relação às leituras religiosas, diz o autor, a fé judaico-cristã desvincula Deus das causas imediatas dos fenômenos naturais, buscando o sentido das contingências da vida, da dor, do sofrimento e da morte no "horizonte pascal da vida que vence a morte, da empatia que rompe com o isolamento e da solidariedade e supera os individualismos". A teologia cristã se afasta do uso mágico da fé. A ciência irá dominar o coronavírus. O próprio da fé é alimentar a vida de quem crê, dando-lhe resistência e luz para fugir das soluções mágicas e ativar a misericórdia para com quem sofre ${ }^{74}$.

No texto "A ciência do coronavírus", Passos afirma que as ciências direcionaram as "explicações e estratégias de controle da pandemia". Isso não é tudo, porque "a dor e o sofrimento não têm soluções científicas".

73 PASSOS, p. 46, 48, 51.

74 PASSOS, p. 56-59. 
O problema é que nesse tempo de pandemia houve muitas leituras pré-científicas do vírus, de seus efeitos e das formas de controle. Muitas informações foram divulgadas e manipuladas ideologicamente. Outras, de cunho mágico-religioso, presentes em tendências cristãs pentecostais, evangélicas e católicas, atribuíram a origem e o controle da pandemia ao sobrenatural. Esse tipo de leitura pode ser sincero ou ideológico, e, neste último caso, a religião é utilizada para justificar o uso político da fé dos fiéis em apoio ao projeto bolsonarista de poder ${ }^{75}$.

No texto "A pandemia econômica", o autor mostra que a crise sanitária, com os riscos e sofrimentos que provocou, leva a pensar em outra crise, a econômica mundial da economia globalizada. O pânico sobre o futuro da economia mundial tem seu epicentro nos donos do capital financeiro, que comanda o mundo sob todos os aspectos. São eles que buscam impor a ideia de que "a economia não pode parar", que "o isolamento social deve ser evitado, ponderado, escalonado". Nesse sentido, o critério de "julgamento da crise tem sido, no fundo, econômico". Nessa perspectiva, a "pandemia expõe os limites da lógica econômica de orientação neoliberal, mas não traz consigo novas soluções e estratégias que permitam desviar a rota em curso ou edificar um novo modelo". O texto "A pandemia e o outro mundo" retoma as leituras religiosas da pandemia, grande parte de caráter mágico, levando, por exemplo, os pentecostais a recorrerem à Bíblia e a dela retirarem "palavras mágicas, capazes de enfrentar o vírus", e os católicos a recuperarem "a força das bênçãos, das imagens e das devoções". Os estudiosos da religião sabem que ela é "a força dos fracos e a construção de um ponto de apoio para a precariedade da vida", e que, em tempos de crise "as buscas por explicação e solução religiosas se tornam mais visíveis no espaço público e gozam de maior demanda". Essa visão de um deus que intervém na natureza e na história é, porém, posta à prova e exige que sua natureza seja repensada sob pena de "transformá-lo em um ser insensível ou em um Pai surdo ou sádico". Nesta zona de "desconforto religioso radical" deve entrar em cena o Deus de Jó, de Jesus Crucificado, das vítimas de violência. Com efeito, o Deus de Jesus é o "Deus crucificado na cruz; é carne na carne que sofre, fome na fome que clama, frio no corpo que congela, caminhante no refugiado que atravessa as fronteiras". A encarnação superou as teologias da onipotência divina, os rituais de manipulação mágica, ele é "amor e não poder, é misericórdia e não domínio",

75 PASSOS, p. 66. 
"convida para a empatia e a solidariedade" e não para a "solução mágica para os problemas da vida" ${ }^{\prime 76}$.

No texto "O vírus verde e amarelo", o autor diz que a "pandemia mundial se abrasileirou", pois "o agente infeccioso vindo de fora foi apropriado politicamente e submetido a leituras originais e [...] perigosas". Junto às leituras religiosas, existem as de caráter político "que transferem para forças externas malignas a origem do vírus". Ambas ignoram as explicações científicas e apelam para a crença em verdades reveladas por testemunhas inquestionáveis. Em "termos de abrasileiramento, a pandemia aglutinou em torno do projeto de poder do governo atual uma leva de militantes" que defendem uma conspiração universal maquinada por inimigos do governo sob o signo da pandemia. Esses grupos se vestiram de verde e amarelo, foram às ruas e gritaram contra o isolamento social, contra a Rede Globo, puseram em questão os números de contaminados, provocaram aglomerações, pediram a volta da ditadura, o fechamento do Congresso Nacional e do STF, demonizaram o governador de SP. Essa leitura desbancou a da Organização Mundial da Saúde, crendo só na palavra do líder. No texto seguinte "Discursos afinados", Passos compara os dois discursos: o religioso, diz ele, "minimiza em nome de Deus"; o ideológico, "minimiza em nome de um projeto político em curso". Apesar de procederem de gramáticas distintas, os dois discursos relativizam o perigo do vírus, possuem uma metafísica "maniqueia que separa a realidade entre o bem e o mal", "afirmam que o mundo está sob o comando de forças que se encarnam em sujeitos e instituições que visam prejudicar uma renovação do país"

No texto "A pandemia da pós-verdade" o autor reflete sobre o processo de comunicação de informações no período da pandemia. Segundo ele, as informações sobre o vírus e seus efeitos em todos os cantos do mundo reproduziram-se "por meio das mídias e dos sujeitos, adaptando-se aos interesses de cada qual como oferta da última verdade". É possível perceber na pluralidade de informações que se "debateram entre si como portadoras da verdade mais precisa" e que podem ser expostas na seguinte gradação: "como diversidade de informações, como dúvidas e como conspiração". Segundo o autor, a diversidade de informações é comum numa sociedade democrática. Porém, as ciências e seus agentes e organismos são a "fonte confiável e o fio de prumo para discernimento

76 PASSOS, p. 70-71, 76-78.

77 PASSOS, p. 81-82, 88. 
e condução do processo". A dúvida, "produzida como clima e como regra", foi "construída sobretudo por sujeitos politicamente interessados", dando também origem às teorias da conspiração, que generalizaram a perspectiva da pós-verdade ${ }^{78}$.

A terceira parte do livro, "O dia seguinte da pandemia", é composta de oito textos. O primeiro, "O dia em que sairmos da caverna", evoca o mito da caverna, de Platão, que é um convite a sair do mundo da opinião (doxa) rumo ao do conhecimento seguro (episteme). O mundo no qual vivíamos, o do "regime dominante e estável, mostrou sua fraqueza e suas aparências". Já não estamos mais na caverna e teremos que encarar a verdade de frente. Muitos quererão voltar à caverna e a seus falsos dogmas, mas é importante deixar o novo vir, "ainda que em gotas, ainda que trazendo mutações por ora invisíveis". No texto seguinte, "A crise e a cura", Passos afirma que a crise instalada pela pandemia "ainda não mostrou seus impactos profundos na vida dos povos". O modelo econômico, diz ele, "mostrou suas contradições" e a "fragilidade de seus dogmas inabaláveis". Ideologicamente também os sistemas políticos mostraram suas fragilidades. A crise "expôs as contradições do modelo econômico mundial com seus regimes políticos: ofereceu um diagnóstico das ineficiências e das falências". A partir desse diagnóstico poderá vir a decisão de "buscar a cura, a construção de novos rumos para o planeta" Nesse sentido, se torna uma oportunidade.

O texto "O religioso essencial" comenta o decreto presidencial de 25/03/2020, autorizando a volta dos serviços essenciais, dentre os quais os religiosos. Perguntando-se sobre o essencial, o autor afirma que a ética sempre buscou responder a essa pergunta, colocando o valor comum sobre o individual, o universal sobre o local. Daí que a vida humana apareça como o valor maior que se "coloca acima de tudo". $\mathrm{Na}$ iminência de um contágio generalizado o essencial é a preservação da vida. Nesse sentido, o "direito e a justiça para com todos vêm antes dos cultos e sem eles o culto se torna ofensa a Deus". Antes do culto está a vida e o culto só existe por causa dela ${ }^{80}$.

No texto seguinte, "De volta para casa", o autor evoca as mudanças ocorridas na família em contexto urbano e de globalização das

78 PASSOS, p. 92, 94.

79 PASSOS, p. 103, 105, 109.

80 PASSOS, p. 113, 115. 
informações. Nesse contexto, ela se tornou um "pequeno aglomerado de indivíduos isolados", no qual "cada indivíduo vai se tornando uma espécie de centro do mundo que liga, de modo confuso, o próximo e o distante", concretizando a máxima "quanto mais conectado mais isolado". O isolamento social imposto pela pandemia colocou-a de novo no espaço comum da convivência e revelou-a como "possibilidade de convivência e como modo de viver juntos". Passada a pandemia a "família não será mais a mesma. $\mathrm{O}$ cuidado comum será registrado para as gerações futuras como a razão de ser da volta para casa" ${ }^{\prime 1}$.

O texto "Uma crise pascal" recorda o fundamento da esperança judaico-cristã, a páscoa. O dinamismo que brota dela, diz o autor, é "movimento, é crise a ser superada em todos os momentos da vida". Por isso, "a crise faz parte da vida de fé; ela situa cada fiel entre o passado e o futuro em um presente vivenciado como intervalo a ser superado por uma vida renascida, uma vida refeita a cada momento". Nesse sentido, "a fé pascal exige assumir a crise como passagem e não como derrota que faz voltar para trás". No texto seguinte, "Ensinamentos da pandemia", Passos se pergunta sobre que ensinamento trouxe a crise da pandemia e para quem. Dentre os ensinamentos provenientes dessa crise, o autor elenca: o da fragilidade, o da mutabilidade, o da desconstrução, o da desigualdade, o do valor da vida, o da ciência, o da solidariedade. Esses ensinamentos são horizontes de percepções e valores para quem está disposto a "ver, discernir e aprender com os fatos", podendo então ter outra percepção do mundo ${ }^{82}$.

"Em tempos de crise emergem interpretações teológicas tagarelas e barulhentas que apresentam soluções para problemas sem solução", diz Passos no texto "A teologia do silêncio". Muitas dessas soluções são mágicas ou feitas de "barulho" e de "força", e não de "silêncio" ou de "fraqueza". Comentando a celebração do Papa Francisco em 27/03/2020, o autor diz que em "Jesus, Deus nasce, cresce, vive e morre; o divino se instala dentro dos limites humanos". A partir da cruz, continua, "só podemos buscar Deus dentro do humano", na cruz "Deus falou e se mostrou como solidariedade radical com a humanidade". Os crentes na onipotência divina pedem que Deus os livre da pandemia, mas Deus fala no silêncio da dor dos condenados à morte ${ }^{83}$.

\footnotetext{
81 PASSOS, p. 118, 121.

82 PASSOS, p. 125-126, 134

83 PASSOS, p. 135, 139.
} 
O último texto, "A vida planetária", mostra que a pandemia "igualou a todos no planeta". Trata-se, sem dúvida, de uma pandemia que afetou todo o mundo. Por isso, "sairemos mais planetarizados dessa crise". Apesar de planetário, o coronoavírus "não é socialmente neutro", como não o é o enfrentamento político da pandemia. É possível sair da crise com um olhar e um "novo modo de vida para todos e para todo o planeta que grita por sustentabilidade", instaurando "a justiça enquanto é tempo" $"$.

Muitos dos aspectos abordado por Passos se encontram nas obras analisadas na primeira e na segunda parte do presente estudo. Muitos poderão se perguntar até que ponto os conteúdos trabalhados por ele são propriamente teológicos, uma vez que parecem privilegiar uma abordagem econômica e política. Como o próprio autor observa em alguns de seus textos, nada do que é verdadeiramente humano é estrangeiro à fé cristã. A encarnação "rasga o véu" que separa divindade e humanidade. Nesse sentido, ao tornar-se humano, o Verbo divino assume tudo o que é próprio a essa condição, como seu caráter histórico, seu enraizamento em estruturas econômicas e políticas, sua constituição ética.

\section{Conclusão}

Os textos evocados no presente estudo, apesar do caráter ensaístico, próprio do impacto provocado por essa inédita pandemia global da humanidade, são extremamente fecundos e oferecem interessantes chaves de leitura para se pensar o que o mundo tem vivido desde a irrupção dessa primeira crise global que fez o "mundo parar". Passados mais de um ano e meio desde que foi declarada a emergência sanitária, é importante, a título de conclusão, tecer algumas considerações sobre a pertinência desses textos hoje.

A maioria dos textos possui como experiência de referência a quarentena e o isolamento social, com os quais o Brasil começou a enfrentar as ameaças do vírus. As orientações da OMS, em parte seguidas inicialmente pelo Ministério da Saúde e pelos governos dos estados e municípios do país, deram, em seguida, lugar à política temerária do Presidente opondo, à salvação de vidas, a da economia. Boa parte dos textos analisados nesse estudo faz referência ao significado da primeira

84 PASSOS, p. 143. 
pandemia global e às reações políticas do governo brasileiro no enfrentamento da crise sanitária por ela desencadeada.

Do ponto de vista teológico, os eixos privilegiados nas abordagens dos textos estudados, a saber, filosófico-existencial, ético, sociocultural, econômico, político-ideológico e religioso, oferecem pistas importantes para entender os primeiros meses da pandemia, devendo, por isso, provocar a inteligência da fé, como aparece, sobretudo nos textos de Ivone Gebara e de João Décio Passos. Esses textos, no viés propriamente teológico, retomam a perspectiva profética e sapiencial da tradição judaico-cristã, mostrando, por um lado, como elas operam uma "dessacralização" da religião, no sentido de não tolerar a manipulação do "sagrado", com seus rituais que buscam "obrigar" Deus a agir no mundo em favor dos fiéis, e, por outro lado, como elas são um convite a descobrir um Deus presente no mundo e submetido às suas vicissitudes, diferente das imagens do divino onipotente presente nos imaginários religiosos mágicas e rituais de boa parte das mentalidades religiosas. O texto de Passos mostra ainda como esses imaginários têm sido manipulados ideologicamente para fins contrários ao que existe de mais verdadeiro nas religiões em geral e no cristianismo em particular: a defesa da vida.

A maior parte dos textos apresentados traz a marca da lucidez e continua atual, a mais um ano de sua elaboração e publicação. A longa duração da pandemia mostra, de modo ainda mais cruel, a lógica do sistema econômico apresentada por vários dos autores estudados. Ela confirma também as denúncias às escolhas políticas do governo brasileiro, que fizeram com que, no início de julho de 2021, mais de 520 mil brasileiros perdesse a vida, vitimados pela pandemia. Infelizmente também muitos grupos que se dizem cristãos foram cúmplices e apoiadores de um sistema genocida, em contradição clara à fé que dizem professar, e sustentam, apesar dos efeitos perversos do governo que apoiam, um governo cujos efeitos perversos atingem primeiro os mais vulneráveis. $\mathrm{O}$ avanço no processo de vacinação, apesar de sua lentidão, mostra, por sua vez, que a ciência, apesar de malquista pelos donos do poder, é que tornará possível a superação dos efeitos mais letais do vírus nos corpos e, consequentemente, no conjunto do sistema social e político.

Talvez a questão mais grave sobre a qual refletir, também em teologia, depois de mais de um ano e meio de pandemia, é como entender a força da superstição num mundo que pensava já ter encontrado a solução para quase todos os seus enigmas. Como tão bem diz João Décio Passos, 
a solução para os problemas inerentes à natureza deve ser buscada na ciência, mas o impacto desses problemas na vida da humanidade deve ser pensado por muitos saberes, dentre os quais o da teologia. Contudo, como a história atesta, muitos sistemas sociais, econômicos e políticos são sustentados por certas visões teológicas. Em princípio, a fé cristã, em seu longo processo de formação e amadurecimento, como mostram os textos do Antigo e do Novo Testamento, mas também a história do dogma trinitário, faz uma radical crítica das imagens intervencionistas de Deus, confiando à liberdade humana grande parte da responsabilidade pelo cuidado do mundo e pela gestão da vida em sociedade. Crer em Deus, como tão bem mostram todos os profetas, é estabelecer relações justas com os demais seres humanos e, como mostram os textos sapienciais, cuidar do mundo. Esse caminho, já feito pela longa história da revelação e da inteligência da fé não pode, porém, ser dado como já estabelecido uma vez por todas. Cada geração deve de novo inaugurá-lo. Certamente, para o cristianismo, suas escrituras e tradição são referências para interpretar o presente, mas elas não eliminam as questões que brotam da angústia diante, por exemplo, de uma ameaça tão terrível como a que a humanidade tem experimentado diante da pandemia da COVID-19. Somente como companheira da humanidade em sua busca de sentido a teologia poderá de fato ser teologia.

\section{Referências}

AB'SÁBER, T. A aceleração da história e o vírus veloz. In: Revista Cult, n. 257 (maio 2020). Ética em tempos de peste. São Paulo: Bregantini, 2020. p. 32-43.

ANDRADE, E. Vários mundos para uma só pandemia: contra a universalidade do discurso filosófico. In: REICH, E.; BORGES, M. L.; XAVIER, R. C. Reflexões sobre uma pandemia. Florianópolis: Néfiponline, 2020. p. 71-76.

BETTO, F. A pandemia e suas implicações éticas. In: Revista Cult, n. 257 (maio 2020). Ética em tempos de peste. São Paulo: Bregantini, 2020. p. 98-100.

BIANCHI, A. Maquiavel demoníaco. In: Revista Cult, n. 257 (maio 2020). Ética em tempos de peste. São Paulo: Bregantini, 2020. p. 70-73. 
BORGES, M. L. Sobre o mal da natureza e o mal humano. In: REICH, E.; BORGES, M. L.; XAVIER, R. C. Reflexões sobre uma pandemia. Florianópolis: Néfiponline, 2020. p. 115-123.

BRAGA, R. Os limites do carisma: ética, trabalho e necropolítica. In: Revista Cult, n. 257 (maio 2020). Ética em tempos de peste. São Paulo: Bregantini, 2020. p. 22-27.

BURIL, B. A pandemia e o individualismo que nunca existiu. In: REICH, E.; BORGES, M. L.; XAVIER, R. C. Reflexões sobre uma pandemia. Florianópolis: Néfiponline, 2020, p. 30-34.

CAMPELLO, F. De onde fala a filosofia? In: REICH, E.; BORGES, M. L.; XAVIER, R. C. Reflexões sobre uma pandemia. Florianópolis: Néfiponline, 2020. p. 82-88.

CHAVES, E. Sobreviver, mais uma vez! In: Revista Cult, n. 257 (maio 2020). Ética em tempos de peste. São Paulo: Bregantini, 2020. p. 50-55.

CONSANI, C. F. A soberania dos Estados e os limites das instituições internacionais na pandemia do coronavírus. In: REICH, E.; BORGES, M. L.; XAVIER, R. C. Reflexões sobre uma pandemia. Florianópolis: Néfiponline, 2020. p. 45-52.

CORDÁS, T. A economia deve esperar. Em Revista Cult, n. 257 (maio 2020). Ética em tempos de peste. São Paulo: Bregantini, 2020. p. 82-91.

DALL'AGNOLL, D. Reflexões bioéticas sobre a COVID-19. In: REICH, E.; BORGES, M. L.; XAVIER, R. C. Reflexões sobre uma pandemia. Florianópolis: Néfiponline, 2020. p. 53-60.

DE ARAÙJO, R. L. A revolta de Albert Camus contra a peste. In: Revista Cult, n. 257 (maio 2020). Ética em tempos de peste. São Paulo: Bregantini, 2020. p. 6-15.

DEBONA, V.; DIAS, C. A. Alegria maligna. In: REICH, E.; BORGES, M. L.; XAVIER, R. C. Reflexões sobre uma pandemia. Florianópolis: Néfiponline, 2020. p. 135-144.

DE MELO, T. O despotismo delivery do capital. In: Revista Cult, n. 257 (maio 2020). Ética em tempos de peste. São Paulo: Bregantini, 2020. p. 62-65.

DUNKER, C. I. L. A ética da psicanálise e a peste generalizada. In: Revista Cult, n. 257 (maio 2020). Ética em tempos de peste. São Paulo: Bregantini, 2020. p. 28-31. 
DUTRA, D. J. V. A COVID-19 e o iluminismo. In: REICH, E.; BORGES, M. L.; XAVIER, R. C. Reflexões sobre uma pandemia. Florianópolis: Néfiponline, 2020. p. 61-70.

FELIPPE, M. S. Pandemia: a antítese entre sociedade e mercado. In: Revista Cult, n. 257 (maio 2020). Ética em tempos de peste. São Paulo: Bregantini, 2020. p. 56-61.

GEBARA, I. Uma perspectiva teológica feminista. In: Revista Cult, n. 257 (maio 2020). Ética em tempos de peste. São Paulo: Bregantini, 2020. p. 16-21.

KLEIN, J. O papel político da comunidade científica e dos intelectuais e o caso da pandemia do coronavírus. In: REICH, E.; BORGES, M. L.; XAVIER, R. C. Reflexões sobre uma pandemia. Florianópolis: Néfiponline, 2020. p. 95-104.

MACIEIRA, A. C. “Arbeit Macht Frei”: Brasil 2020. In: Revista Cult, n. 257 (maio 2020). Ética em tempos de peste. São Paulo: Bregantini, 2020. p. 66-69.

NAHRA, C. Tem futuro a humanidade? In: REICH, E.; BORGES, M. L.; XAVIER, R. C. Reflexões sobre uma pandemia. Florianópolis: Néfiponline, 2020. p. 35-44.

NETO, L. F. Covid-10 e ubupoder-19. In: REICH, E.; BORGES, M. L.; XAVIER, R. C. Reflexões sobre uma pandemia. Florianópolis: Néfiponline, 2020. p. 105-114.

NICOLI, P. A. G.; VIEIRA, R. S. C. Cuidado em surto: da crise à ética. In: Revista Cult, n. 257 (maio 2020). Ética em tempos de peste. São Paulo: Bregantini, 2020. p. 74-77.

PASSOS, J. D. O vírus vira mundo: em pequenas janelas da quarentena. São Paulo: Paulinas, 2020.

PINZANI, A. Fraqueza do Estado e elitização da cidadania na América do Sul. Lições políticas da pandemia. In: REICH, E.; BORGES, M. L.; XAVIER, R. C. Reflexões sobre uma pandemia. Florianópolis: Néfiponline, 2020. p. 21-29.

QUINALHA, R. Desafios à democracia. In: Revista Cult, n. 257 (maio 2020). Ética em tempos de peste. São Paulo: Bregantini, 2020. p. 78-81. 
REICH, E. Entre a cruz e a espada. In: REICH, E.; BORGES, M. L.; XAVIER, R. C. Reflexões sobre uma pandemia. Florianópolis: Néfiponline, 2020. p. 77-81.

RODRIGUES, C.; AYRES, S. Coreia do Sul, Brasil... ou o pior. In: Revista Cult, n. 257 (maio 2020). Ética em tempos de peste. São Paulo: Bregantini, 2020. p. 44-49.

SATTLER, J. Suspensão. In: REICH, E.; BORGES, M. L.; XAVIER, R. C. Reflexões sobre uma pandemia. Florianópolis: Néfiponline, 2020. p. 89-94.

TONETTO, M. C. Ética global, direitos humanos e a pandemia da COVID-19. In: REICH, E.; BORGES, M. L.; XAVIER, R. C. Reflexões sobre uma pandemia. Florianópolis: Néfiponline, 2020. p. 124-134. 